\title{
PRECOCIDADE DE PRODUÇÃO DE CULTIVARES DE MACIEIRA SOBRE DOIS PORTA-ENXERTOS ${ }^{1}$
}

\author{
JOÃO CAETANO FIORAVANÇO
}

RESUMO - Em ensaios de competição, muitos fatores são avaliados visando a diferenciar as cultivares e a proceder à recomendação de uso. Em relação ao desempenho produtivo, cultivares que entram em produção precocemente, produzem regularmente ao longo dos anos e, ao final, apresentam produções superiores, destacam-se em relação às demais. Desta forma, o trabalho foi realizado com o objetivo de avaliar a precocidade de produção, por meio da aplicação do índice de precocidade de produção, e a produção acumulada de nove cultivares de macieira enxertadas sobre dois porta-enxertos, durante as seis primeiras safras. Os mais elevados índices de precocidade de produção foram exibidos pelas cultivares Daiane, Mishima e Fuji Select no porta-enxerto M-9, e pelas cultivares Fuji Suprema, Daiane e Gala Real no porta-enxerto Marubakaido/M-9. Ao final das seis safras, 'Baigent' e 'Cripps Pink', no porta-enxerto M-9, e 'Maxi-Gala', 'Baigent', 'Daiane', 'Gala Real' e 'Royal Gala', no Marubakaido/M-9, apresentaram as maiores produções acumuladas. Somente 'Daiane' e 'Gala Real', sobre a combinação Marubakaido/M-9, destacaram-se para as variáveis índice de precocidade de produção e produção acumulada, simultaneamente. O índice de precocidade de produção é um parâmetro importante para, junto com outros fatores, como a produção e a qualidade dos frutos, diferenciar cultivares de macieira.

Termos para Indexação: Malus $x$ domestica, variedades, ensaio de competição, índice de precocidade de produção, produção acumulada.

\section{YIELD EARLINESS OF APPLE CULTIVARS GRAFTED ONTO TWO DIFFERENT ROOTSTOCKS}

\begin{abstract}
In competition assays, many factors are evaluated aiming the differentiation of apple cultivars and to undertake the use of recommendations. Regarding productive performance, cultivars that exhibit regular yields throughout the years, produce regularly over the years and have higher cumulative fruit yield, stand out over other cultivars. The present study was carried out along six harvesting seasons to determine yield precocity by means of the application of an earliness index and the cumulative fruit yield of nine apple cultivars grafted onto two different rootstocks. The highest indexes for yield earliness were presented by the cultivars Daiane, Mishima and Fuji Select grafted onto the M-9 rootstock and by the cultivars Fuji Suprema, Daiane and Gala Real cultivars grafted onto the Marubakaido/M-9 rootstock. 'Baigent' and 'Cripps Pink', grafted onto M-9, and 'Maxi-Gala', 'Baigent', 'Daiane' and 'Gala Real', grafted onto Marubakaido/M-9, had higher cumulative yields after six harvesting seasons. The cultivars 'Daiane' and 'Gala Real', grafted onto Marubakaido/M-9, presented better performances for both investigated parameters: earliness index of fruit yields and cumulative fruit yields. The earliness index for fruit yield is an important parameter to distinguish apple cultivars, along with other characteristics, such as production and fruit quality.
\end{abstract}

Index terms: Malus $x$ domestica, cultivars, competition assay, earliness index, cumulative yield.

'(Trabalho 153-14). Recebido em; 09-05-2014. Aceito para publicação em: 16-04-2015.

2Eng. Agrôn., Dr., Pesquisador, Embrapa Uva e Vinho, Caixa Postal 130, CEP 95700-000 Bento Gonçalves, RS. E-mail: joao.fioravanco@embrapa.br

Rev. Bras. Frutic., Jaboticabal - SP, v. 37, n. 3, p. 676-684,, Setembro 2015 


\section{INTRODUÇÃO}

Em ensaios de competição de cultivares de espécies frutíferas, a produção acumulada obtida no final do período de avaliação é um dos critérios mais importantes para diferenciar os materiais. Muitas vezes, no entanto, é comum observar-se, ao final desse período, produções semelhantes para cultivares que exibiram comportamentos distintos ao longo do tempo. Por exemplo, algumas cultivares apresentam produções significativas já nos primeiros anos após o plantio, enquanto outras levam mais tempo para entrar em produção. Da mesma forma, algumas cultivares caracterizamse por produzirem regularmente todos os anos, ao passo que outras apresentam produções que oscilam intensamente de uma safra para outra.

$\mathrm{Na}$ cultura da macieira, em função do elevado custo de instalação dos pomares modernos, baseados em altas densidades de plantio, utilização de estruturas para o apoio e condução das plantas, e uso intensivo de insumos, quanto mais precoce for o início da produção comercial e mais elevado o rendimento nos primeiros anos após o plantio, mais rápida será a recuperação do capital investido. Além disso, produtividade elevada e regularidade anual de produção são fatores importantes para a melhor utilização da infra-estrutura de produção, maximização das receitas e atendimento aos clientes. Por isso, cultivares que reúnem a maior quantidade desses atributos, além de outras características importantes para os produtores, comerciantes e consumidores, são as mais aceitas e valorizadas.

A precocidade e a regularidade de produção são características inerentes às cultivares. Entretanto, elas podem ser influenciadas pelas condições meteorológicas e pelas práticas culturais adotadas no pomar, como poda, raleio, aplicação de reguladores de crescimento, adubação e controle de pragas e doenças (TROMP, 2000; WÜNSCHE; LAKSO, 2000; WÜNSCHE; FERGUSON, 2005; BUKOVAC et al., 2006).

Os porta-enxertos também exercem efeito na precocidade de frutificação, na produção da planta nos anos iniciais e na produtividade (ELFVING; MCKIBBON, 1991). Além disso, eles definem o tamanho da planta, que, por sua vez, afeta a eficiência do trabalho nos pomares (ROBINSON, 2011). Os porta-enxertos de pouco vigor ou ananizantes antecipam o início da frutificação das cultivares (DENARDI, 2006) e, de acordo com alguns autores, inibem a alternância de produção entre as safras (JONKERS, 1979; BARRITT et al., 1997). Os porta-enxertos semivigorosos e vigorosos são considerados menos eficientes que os de menor vigor para antecipar o início da frutificação (DENARDI, 2006). Entretanto, quando associados a interenxertos apropriados, além de controlar o vigor da planta (DI VAIO et al., 2009), podem induzir à produção precoce de frutos, a altas produtividades e à regularidade de produção entre as safras (WEBSTER, 1994; VERCAMEN et al., 2007).

A precocidade de produção de cultivares pode ser determinada por meio do Índice de Precocidade de Produção (IPP), obtido a partir da metodologia proposta por Bartlett para avaliar a precocidade de germinação de sementes (REDDY et al., 2003). Exemplos de trabalhos utilizando o índice incluem as culturas do algodoeiro (SARANG et al., 2010), do cafeeiro (CILAS et al., 2011) e da mangueira (REDDY et al., 2003). Na cultura da macieira, no entanto, não foi encontrada nenhuma referência sobre sua utilização.

O objetivo do trabalho foi avaliar a precocidade de produção de nove cultivares de macieira enxertadas sobre dois porta-enxertos, um de baixo vigor (M-9) e outro de elevado vigor (Marubakaido com interenxerto de M-9), durante as seis primeiras safras, por meio da aplicação do índice de precocidade de produção. A produção acumulada, obtida da soma das produções anuais, também foi objeto de avaliação.

\section{MATERIAL E MÉTODOS}

Em 2006, foram implantados dois pomares em Vacaria-RS (latitude 28 $8^{\circ} 33^{\prime} \mathrm{S}$, longitude 50 $57^{\prime} \mathrm{O}$ e $955 \mathrm{~m}$ de altitude), sob um solo do tipo Latossolo Vermelho alumínico câmbico (STRECK et al., 2008). O clima da região é o temperado ( $\mathrm{Cfb} 1)$, segundo a classificação de Köeppen (MORENO, 1961). Os pomares foram constituídos pelas cultivares Baigent, Cripps Pink, Daiane, Fuji Select, Fuji Suprema, Gala Real, Maxi-Gala, Mishima e Royal Gala, sobre os porta-enxertos M-9 (Malus pumila) e Marubakaido (Malus prunifolia) com interenxerto de M-9. Os espaçamentos foram de $3,5 \mathrm{~m} \mathrm{x} 1,0 \mathrm{~m}$ (2.857 plantas ha $\left.{ }^{-1}\right)$ e 4,0 m x 1,4 m (1.785 plantas ha $^{-1}$ ), respectivamente, para cada porta-enxerto. Foi utilizado o delineamento em blocos ao acaso, com três repetições e dez plantas por unidade experimental.

As plantas foram podadas e conduzidas de acordo com a forma normalmente utilizada nos pomares comerciais da região, realizando-se o mínimo de intervenção nos primeiros dois anos 
e conduzindo-se as plantas no sistema de líder central. No ano de plantio, as flores e os frutos foram removidos. Todos os anos, foram realizadas aplicações de produtos para auxiliar na quebra da dormência, constituídas de cianamida hidrogenada a 0,20 e $0,25 \%$ e óleo mineral a 3,0 e $4,0 \%$, dependendo das unidades de frio acumuladas no inverno. $\mathrm{O}$ raleio foi manual, deixando-se 1 a 2 frutos por cacho.

Durante as safras de 2008 a 2013 (primeira à sexta safra), foram apuradas as produções anuais de frutos por planta, em $\mathrm{kg}$, obtidas mediante a soma dos pesos de todos os repasses efetuados durante o período de colheita, em cada bloco, dividindo-se o resultado pelo número de plantas da parcela.

A partir das produções anuais, foi calculado o Índice de Precocidade de Produção (IPP) por meio da fórmula (CILAS et al., 2011):

$$
\mathrm{IPP}=\frac{n y_{1}+(n-1) y_{2}+\ldots+2 y_{n-1}+y_{n}}{n Y}
$$

em que, $y_{i}$ é a produção por planta observada na i-ésima safra, na série ordenada de tamanho n; Y é o somatório das produções por planta durante as safras do período avaliado, e n é o número de safras. O IPP atribui maior peso para os primeiros anos de produção e menos peso para os últimos anos. Ele varia de zero a um, e quanto mais próximo de um (1) seu valor, mais precoce é a produção da planta.

Foram calculadas as produções acumuladas, mediante a soma das produções anuais obtidas nos seis anos avaliados. Para cada cultivar, foi determinada a relação entre a produção acumulada alcançada no porta-enxerto Marubakaido com interenxerto de M-9 e a produção acumulada obtida no porta-enxerto M-9, expressando-se o resultado como um número índice.

O IPP e a produção acumulada foram submetidos à análise de variância. Para o IPP, a análise foi conjunta, considerando-se os fatores cultivar, porta-enxerto e a interação cultivar $\mathrm{x}$ porta-enxerto. Quando o efeito da interação foi significativo, procedeu-se ao desdobramento para cultivar dentro de porta-enxerto, pelo teste de Scott-Knott, em nível de 5\% de probabilidade $(P \leq 0,05)$. Para a produção acumulada, realizou-se a comparação das médias das cultivares em cada porta-enxerto, separadamente, pelo mesmo teste.

\section{RESULTADOS E DISCUSSÃO}

A análise do IPP não apresentou significância para o efeito principal porta-enxerto $(\mathrm{p}>0,05)$. De certa forma, esse resultado é surpreendente, pois os porta-enxertos ananizantes são considerados mais eficientes na antecipação da produção da macieira em relação aos semivigorosos e vigorosos. Ou seja, em função da forma de cálculo do IPP, que atribui maior peso às produções das primeiras safras da série utilizada, esperava-se que os índices sobre o M-9 fossem mais elevados em relação aos índices sobre o Marubakaido/M-9. Provavelmente, o controle do vigor exercido pelo interenxerto de M-9 no Marubakaido proporcionou às cultivares produções importantes já nos primeiros anos após o plantio, aproximando os desempenhos, independentemente do porta-enxerto.

Ao contrário do observado para os portaenxertos, foi constatado efeito significativo para a cultivar $(\mathrm{p}=0,0015)$ e para a interação Portaenxerto x Cultivar $(\mathrm{p}=0,0003)$. A significância da interação indica que as respostas das cultivares dependem do porta-enxerto. Com o desdobramento de cultivar dentro de porta-enxerto, verificou-se que 'Daiane', 'Fuji Select' e 'Mishima' apresentaram os maiores IPPs no porta-enxerto M-9, enquanto 'Fuji Suprema', 'Daiane' e 'Gala Real' exibiram os maiores índices no porta-enxerto Marubakaido/M-9 (Figura 1).

'Daiane' foi a única cultivar que exibiu IPP entre os mais elevados, em ambos os porta-enxertos. Denardi e Camilo (1998) atribuem a essa cultivar precocidade média de produção $\left(3^{\circ}\right.$ ano), mas afirmam que a mesma apresenta índices de floração melhores que os das cultivares Gala e Fuji, fato que pode explicar, ao menos em parte, os índices de precocidade de produção elevados, derivados de boa floração e frutificação já nas primeiras safras.

As maiores produções acumuladas, ao final das seis safras, foram apresentadas pelas cultivares Baigent e Cripps Pink, no porta-enxerto M-9, e pelas cultivares Maxi-Gala, Baigent, Daiane, Gala Real e Royal Gala, no Marubakaido/M-9 (Figura 2). A evolução das produções, cumulativamente, nas safras de 2008 a 2013, dá uma ideia do comportamento individual de cada cultivar, em cada porta-enxerto e, ao final do período, da magnitude da diferença entre elas (Figura 3).

Comportamentos distintos entre cultivares de macieira são normais e esperados, pois o potencial de produção está relacionado com a característica genética de cada uma delas e, por isso, pode manifestar-se distintamente ao longo das safras (ELFVING; SCHECHTER, 1993; GJAMOVSKI; KIPRIJANOVSKI, 2011). Além disso, em cada safra, as cultivares podem responder de maneira específica às condições meteorológicas, 
às técnicas de manejo utilizadas, especialmente a quebra de dormência e o raleio de frutos, ou a ambos os fatores. As cultivares também exibem comportamentos fenológicos distintos e, por isso, podem ser afetadas de maneira diferente no caso de ocorrência de eventos climáticos adversos (geada e precipitações em excesso na época de floração, estiagens, granizo, etc.). Por fim, deve-se considerar que as cultivares apresentam diferentes propensões à alternância anual de produção (HAMPSON; KEMP, 2003; ROBINSON, 2008; MCARTNEY et al., 2013; KRASNIQI et al., 2013). Ou seja, as respostas das cultivares, ao longo do tempo, estão relacionadas a vários fatores e, por isso, são distintas.

A produção acumulada das cultivares sobre o Marubakaido/M-9 foi, em média, mais de $40 \%$ superior à produção acumulada obtida no M-9 (dados não analisados estatisticamente). Individualmente, todas as cultivares exibiram produção acumulada mais alta sobre o porta-enxerto de maior vigor, com exceção da 'Fuji Select' (Figura 4). Os resultados confirmam os obtidos por outros autores (WERTHEIM et al., 1989; KOSINA, 2010; GJAMOVSKI; KIPRIJANOVSKI, 2011) e são atribuídos ao maior volume de copa, que proporciona a produção de maior quantidade de estruturas produtivas (COSTES; GARCÍAVILLANUEVA, 2007).

Para o produtor de maçã, a cultivar mais adequada é a que apresenta, ao mesmo tempo, os maiores valores de IPP e de produção acumulada. Sobre o porta-enxerto M-9, nenhuma das cultivares se destacou concomitantemente em relação às duas variáveis. 'Mishima', 'Fuji Select' e 'Daiane' destacaram-se pelo IPP, enquanto 'Baigent' e Cripps Pink’ destacaram-se pela produção acumulada. No entanto, sobre a combinação Marubakaido/M-9, as cultivares Daiane e Gala Real destacaram-se em relação às demais, em ambas as variáveis. Nesse porta-enxerto, 'Fuji Suprema' destacou-se apenas pelo IPP, enquanto 'Maxi-Gala', 'Baigent' e 'Royal Gala’ sobressaíram pela produção acumulada.

Apesar de a produção precoce e elevada nos primeiros anos após o plantio ser considerada fator importante para os produtores de maçã, recomenda-se realizar o controle da carga de frutos nos anos iniciais para evitar que as cultivares adquiram o hábito de alternância de produção, característica indesejável devido ao efeito negativo sobre a produtividade acumulada ao longo dos anos, qualidade da fruta e fisiologia da planta (BERTELSEN; TUSTIN, 2002; ROBINSON, 2008). De acordo com Robinson (2008), o equilíbrio na carga de frutos de cada cultivar, em função das condições de cultivo, ou seja, de acordo com o espaçamento de plantio, vigor e capacidade produtiva, permite a obtenção de um equilíbrio ótimo entre crescimento e produção.

Por fim, salienta-se que o IPP não deve ser adotado como fator isolado para a escolha de cultivares de macieira. No entanto, ele constituise em parâmetro adicional para, junto com outras características em avaliação, como época de floração e produção, ciclo, produtividade, resistência a pragas e doenças, qualidade da fruta e capacidade de armazenamento, diferenciar os materiais em estudo. 


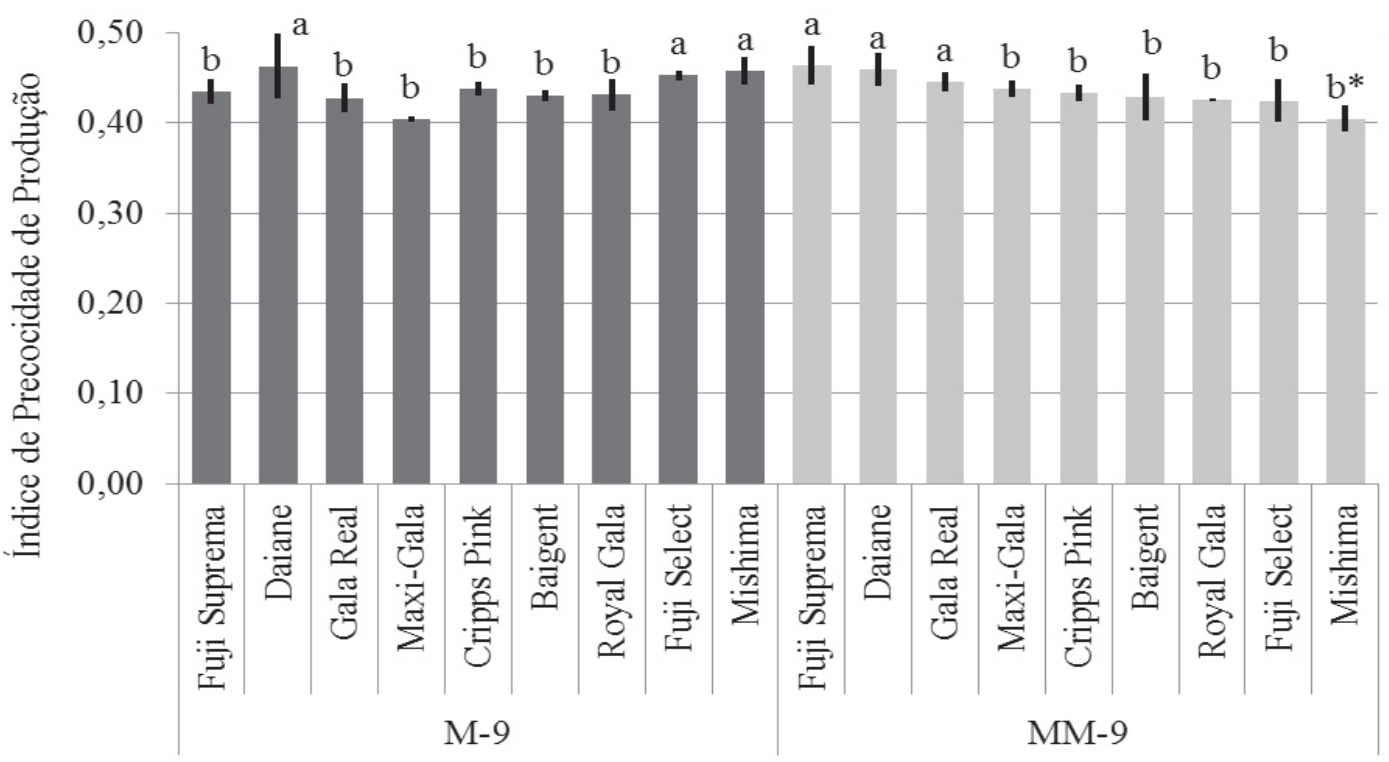

FIGURA 1 - Índice de Precocidade de Produção das cultivares de macieira Baigent, Cripps Pink, Daiane, Fuji Select, Fuji Suprema, Gala Real, Maxi-Gala, Mishima e Royal Gala, sobre os portaenxertos M-9 e Marubakaido com interenxerto de M-9 (MM-9). Vacaria-RS, 2008 a 2013.

*Letras iguais, em cada porta-enxerto, não diferem pelo teste de Scott-Knott, a 5\% de probabilidade.

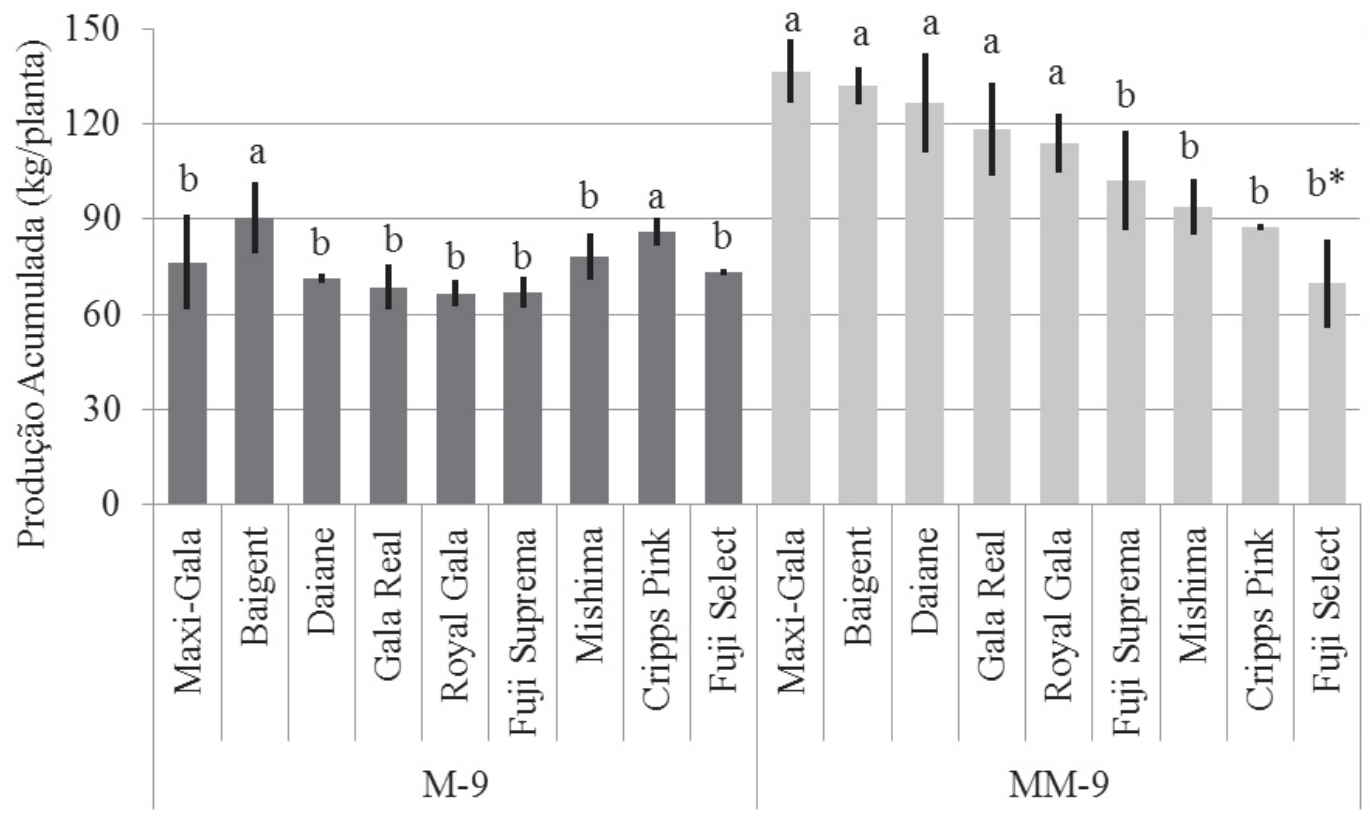

FIGURA 2 - Produção acumulada (kg/planta) nas seis primeiras safras das cultivares de macieira Baigent, Cripps Pink, Daiane, Fuji Select, Fuji Suprema, Gala Real, Maxi-Gala, Mishima e Royal Gala, sobre os porta-enxertos M-9 e Marubakaido com interenxerto de M-9 (MM-9). Vacaria-RS, 2008 a 2013.

* Letras iguais, em cada porta-enxerto, não diferem pelo teste de Scott-Knott, a 5\% de probabilidade. 

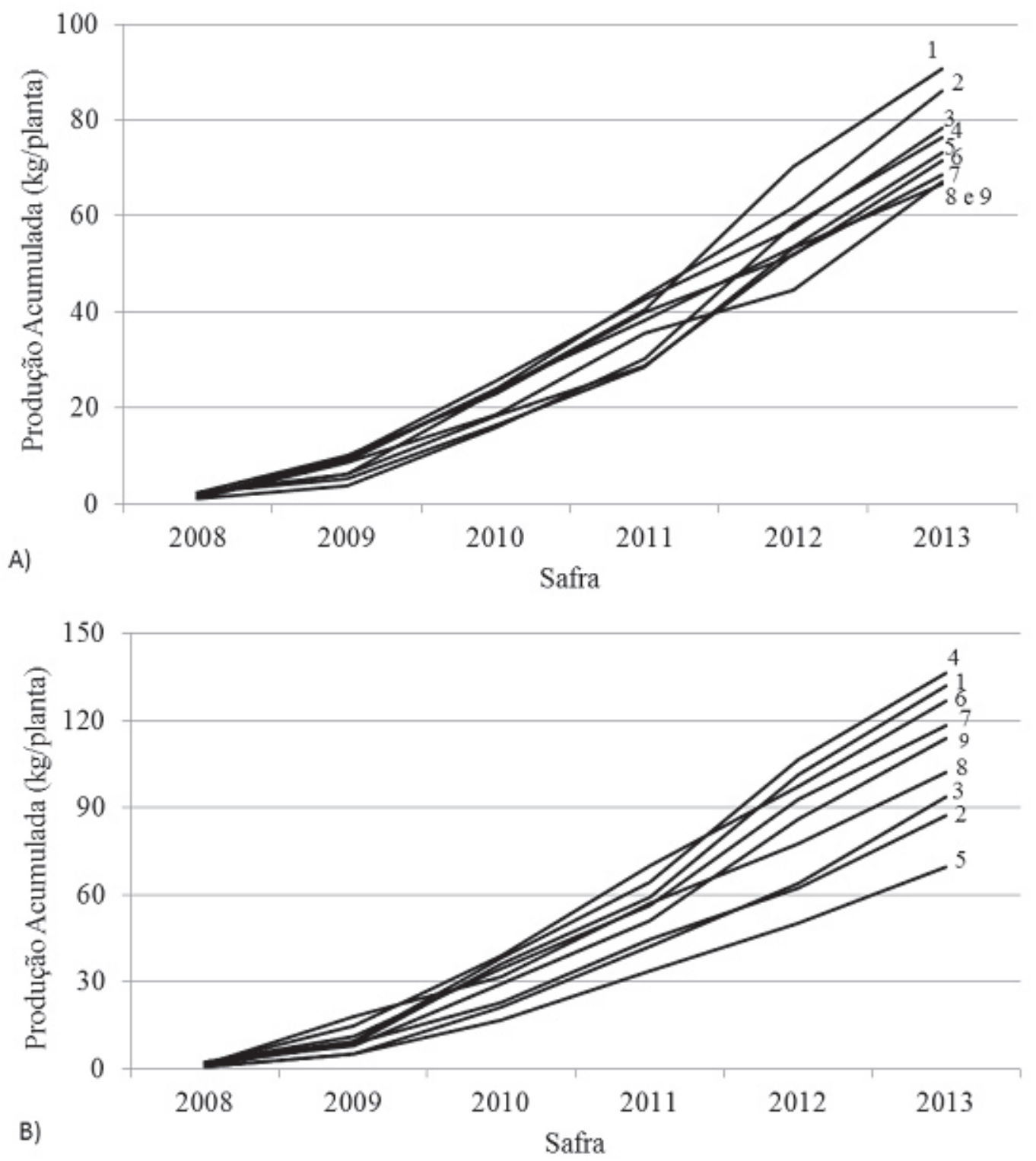

FIGURA 3 - Evolução da produção, cumulativamente, de cultivares de macieira sobre dois porta-enxertos ( $\mathrm{A}=\mathrm{M}-9$; B = Marubakaido com interenxerto de M-9). Vacaria-RS 2008 a 2013. 1) Baigent, 2)Cripps Pink, 3)Mishima, 4)Maxi-Gala, 5)Fuji Select, 6)Daiane, 7)Gala Real, 8)Fuji Suprema, 9)Royal Gala. 


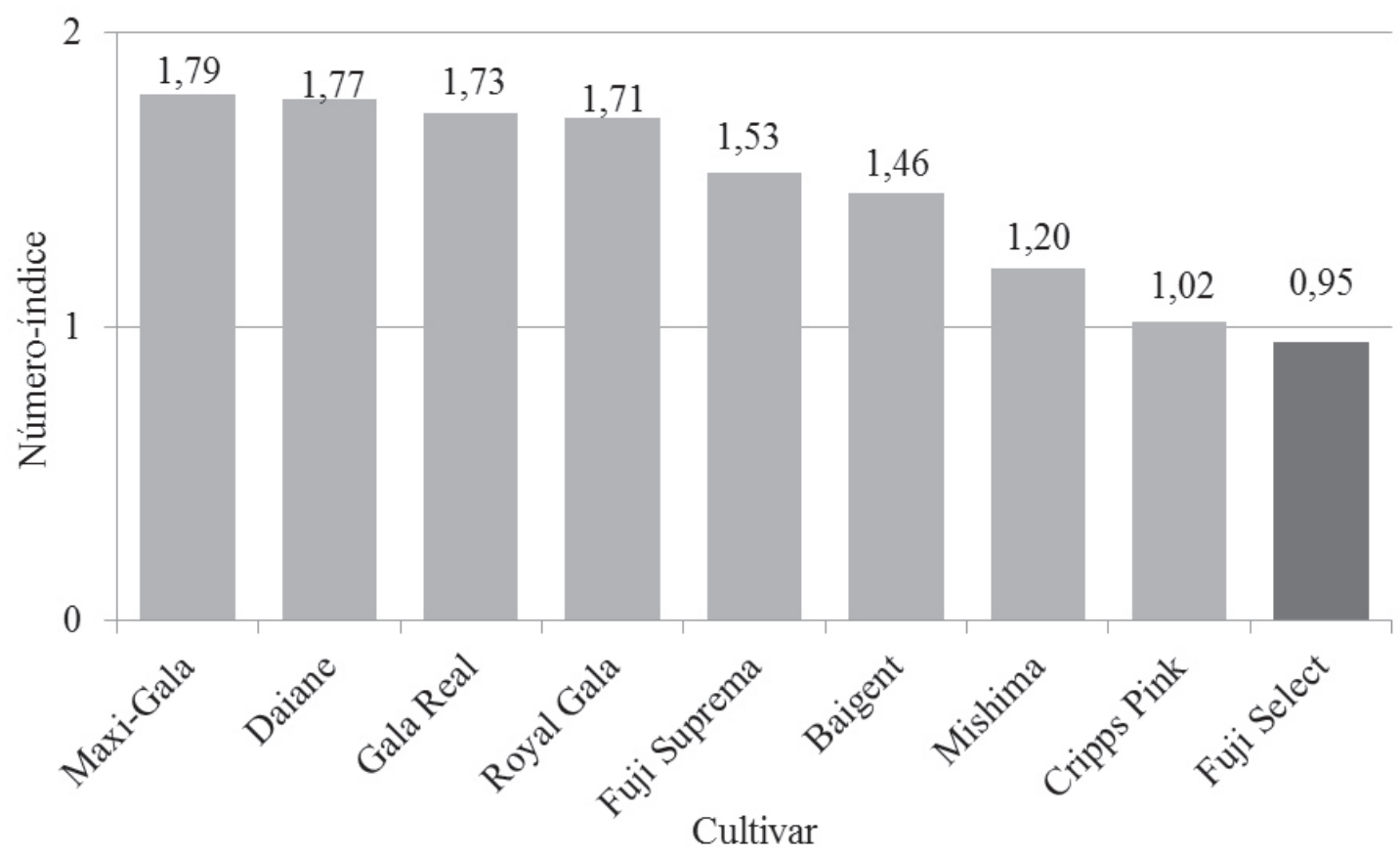

FIGURA 4 - Número-índice expressando a relação entre a produção acumulada obtida no porta-enxerto Marubakaido com interenxerto de M-9 e a produção acumulada alcançada no porta-enxerto M-9 para nove cultivares de macieira, após seis safras. Vacaria-RS 2008 a 2013.

\section{CONCLUSÕES}

Os maiores IPPs foram determinados para as cultivares Daiane, Mishima e Fuji Select no porta-enxerto M-9 e para as cultivares Fuji Suprema, Daiane e Gala Real no porta-enxerto Marubakaido/M-9.

As cultivares Baigent e Cripps Pink, no porta-enxerto M-9, e as cultivares Maxi-Gala, Baigent, Daiane, Gala Real e Royal Gala, no Marubakaido/M-9, apresentaram as maiores produções acumuladas ao final das seis safras.

Apenas as cultivares Daiane e Gala Real, sobre a combinação Marubakaido/M-9, destacaram-se em relação às demais cultivares para as variáveis produção acumulada e IPP, de maneira concomitante.

\section{REFERÊNCIAS}

BARRITT, B.H.; KONISHI, B.S.; DILLEY, M.A. Tree size, yield and biennial bearing relationship with 40 apple rootstocks and tree scion cultivars. Acta Horticulturae, The Hague, n.451, p.105-112, 1997.

BERTELSEN, M.G.; TUSTIN, D.S. Suppression of flower bud formation in light cropping trees of 'Pacific Rose' apple using gibberellin sprays. Journal of Horticultural Science and Biotechnology, Ashford, v.77, p.753-757, 2002.

BUKOVAC, M.; SABBATINI, P.; SCHWALLIER, P. Modifying alternate bearing of spur-type 'Delicious' apple with ethephon. HortScience, Alexandria, v.41, n.7, p.1606-1611, 2006.

CILAS, C.; MONTAGNON, C.; BAR-HEN, A. Yield stability in clones of Coffea canephora in the short and medium term: longitudinal data analyses and measures of stability over time. Tree Genetics \& Genomes, St. Louis, v.7, p.421-429, 2011. 
COSTES，E.; GARCÍA-VILLANUEVA，E. Clarifying the effects of dwarfing rootstocks on vegetative and reproductive growth during tree development: a study on Apple trees. Annals of Botany, London, v.100, p.347-357, 2007.

DENARDI, F. Porta-enxertos. In: EPAGRI. A cultura da macieira. Florianópolis: EPAGRI, 2006. p.169-227.

DENARDI, F.; CAMILO, A.P. Daiane: nova cultivar de macieira para colheita em março. Agropecuária Catarinense, Florianópolis, v.11, n.3, p.6-8, 1998.

DI VAIO, C.; CIRILLO, C.; BUCCHERI, M.; LIMONGELLI, F. Effect of interstock (M.9 and M.27) on vegetative growth and yield of apple trees (cv "Anurca"). Scientia Horticulturae, Amsterdam, v.119, n.13, p.270-274, 2009.

ELFVING, D.C.; McKIBBON, E.D. Effects of rootstock on productivity and pruning requeriments of 'Starkspur Supreme Delicious' apple trees in the NC-140 cooperative planning. Fruit Varieties Journal, University Park, v.45, p.242-246, 1991.

ELFVING, D.C.; SCHECHTER, I. Fruit count, fruit weight, and yield relationships in 'Delicious' apple trees on nine rootstock. HortScience, Alexandria, v.28, n.8, p.793-795, 1993.

GJAMOVSKI, V.; KIPRIJANOVSKI, M. Influence of nine dwarfing apple rootstocks on vigour and productivity of apple cultivar 'Granny Smith'. Scientia Horticulturae, Amsterdam, v.129, p.742746, 2011.

HAMPSON, C.R.; KEMP, H. Characteristics of important commercial apple cultivars. In: FERRE, D.C.; WARRINGTON, I.J. Apples: botany, production and uses. Wallingford: CABI Publishing, 2003. p.61-89.

JONKERS, H. Biennial bearing in apple and pear: a literature survey. Scientia Horticulturae, Amsterdam, v.11, p.303-317, 1979.

KOSINA, J. Effect of dwarfing and semi dwarfing apple rootstock on growth and productivity of selected apple cultivars. Horticultural Science, Praga, v.37, p.121-126, 2010.
KRASNIQI, A.L.; DAMEROW, L.; KUNZ, A.; BLANKE, M.M. Quantifying key parameters as elicitors for alternate fruit bearing in cv. 'Elstar' apple trees. Plant Science, Limerick, n.212, p.1014, 2013.

McARTNEY, S.; GREENE, D.; SCHMIDT, T.; YUAN, R. Naphthaleneacetic acid and ethephon are florigenic in the biennial apple cultivars Golden Delicious and York Imperial. HortScience, Alexandria, v.48, n.6, p.742-746, 2013.

MORENO, J.A. Clima do Rio Grande do Sul. Porto Alegre: Secretaria da Agricultura, 1961. 42p.

REDDY,Y.T.N.; KURIAN, R.M.; RAMACHANDER, P.R.; SING, G.; KOHLI, R.R. Long-term effects of rootstocks on growth and fruit yielding patterns of 'Alphonso' mango (Mangifera indica L.). Scientia Horticulturae, Amsterdam, v.97, p.95-108, 2003. (1)

ROBINSON, T. Advances in apple culture worldwide. Revista Brasileira de Fruticultura, Jaboticabal, p.37-47, 2011. Volume Especial.

ROBINSON, T. Crop load management of new highdensity apple orchards. New York Fruit Quarterly, Geneva, v.16, n.2, p.3-7, 2008.

SARANG, D.H.; BHATADE, S. S.; DEOSARKAR, D. B. Evaluation of some new Bt cotton hybrids for seed cotton yield and fibre quality traits under rainfed conditions. Journal of Cotton Research and Development, Hisar, v.24, n.2, p.149-154, 2010.

STRECK, E.V.; KÄMPF, N.; DALMOLIN, R.S.D.; KLAMT, E.; NASCIMENTO, P.C. do; SCHNEIDER, P.; GIASSON, E.; PINTO, L.F.S. Solos do Rio Grande do Sul. 2.ed. Porto Alegre: EMATER-RS/ASCAR, 2008. 222 p.

TROMP, J. Flower-bud formation in pome fruits as affected by fruit thinning. Plant Growth Regulation, Dordrecht, v.31, p.27-34, 2000.

VERCAMEN, J.; DAELE, G. van; GOMAND, A. Can fruit size and colouring of Jonagold be improved by an interstock? Acta Horticulturae, The Hague, n.732, p.165-170, 2007. 
WEBSTER, J. Rootstock and interstock effects on deciduous fruit tree growth and cropping: a brief review. Compact Fruit Tree, East Lansing v.27, p.5-16, 1994

WERTHEIM, S.J.; MORINI, S.; LORETI, F. Effect of M.27 and M.9 used as rootstock and interstem on apple tree behavior in two different growing conditions. Acta Horticulturae, The Hague, n.243, p.37-50, 1989.
WÜNSCHE, J.N.; FERGUSON, I.B. Crop load interactions in apple. Horticultural Reviews, New York, v.31, p.231-290, 2005.

WÜNSCHE, J.N.; LAKSO, A.N. The relationship between leaf area and light interception by spur and extension shoot leaves and apple orchard productivity. HortScience, Alexandria, v.35, n.7, p.1202-1206, 2000 . 